\title{
Synthetic Studies of Maleimide Derivatives for Bioconjugates Polymers by RAFT polymerization.
}

\author{
Sudershan R. Gondi * \\ Department of Chemistry, Southern Methodist University, 3215 Daniel Avenue, \\ Dallas, Texas 75275-0314, USA
}

\begin{abstract}
An efficient method for the synthesis of maleimides derivatives in toluene in presence of PTSA is described. The method features a broad substrate scope of utility in both simple and complex setting and provide access to valuable derivatives without any column chromatography purification is described.
\end{abstract}

KEY WORDS: maleimides, Bismaleimides, conjugates, RAFT polymerization, PTSA, Condensation.

\section{INTRODUCTION:}

Maleimide-derivatives are among the mostly used in protein chemistry, polymer chemistry and functional group transformation mainly due to its double bond is very reactive and can undergo chain extension reaction ${ }^{1-2}$. In protein chemistry it is used for bioconjugation ${ }^{3}$, due to exceptionally fast reaction rates and significantly high selectivity towards cysteine ${ }^{4}$ residues in proteins, a large variety of maleimide heterobifunctional reagents are used for the preparation of targeted therapeutics ${ }^{5}, \mathrm{PET}^{6}$. Bradykinin 
Antagonists Peptide $^{7}$, cyclic polypeptide drugs $^{8}$, Topoisomerase ${ }^{9}$, pharmaceutical compositions $^{10}$, Highly Potent and Stable Capped siRNAs ${ }^{11}$, nucleotide prodrugs ${ }^{12}$, carbonic anhydrase II Activity ${ }^{13}$, Glycosaminoglycan ${ }^{14}$ and phospholipids ${ }^{15}$. Secondly, maleimides, particularly the bismaleimides are used for synthesis of self-healing polymers ${ }^{16-17}$, selfassembled functional telechelics and modular block copolymers ${ }^{18}$, reactive and functional polymers ${ }^{19}$ such as click chemistry ${ }^{20-22}$. Maleimide derivatives are also used in chemicals applications such as dienophiles in cycloaddition reactions ${ }^{23}$, Thia Paterno Buchi Reaction ${ }^{24}$ C-H activation ${ }^{25}$ and functionalized basic maleimides ${ }^{26}$ are few of them.

Maleimide derivatives are usually synthesized from maleic anhydride and a diamine to obtain the intermediates, maleamic acids which on cyclo-dehydration to a maleimide is a general method for the preparation. Numerous reagents ${ }^{11,23,27-31}$ or high pressure ${ }^{32}$ used methods were reported for effective the dehydration of amic acids to imides. However in these methods that the synthesis leads to several by-products such as isoimides, acetanilides, maleimides, acetic acid adducts, and products with mixed functionalities which interns the yields are low ${ }^{33-34}$. In an Alternate route, the displacement of methoxycarbonyl group of maleimide ${ }^{7}$ with nucleophilic group, such as amines under basic condition to get imides $^{4,35-36}$ or $\mathrm{N}$-alkylation with alkyl halides by using base in anhydrous conditions ${ }^{37-38}$

\section{PRESENT WORK.}

In our projects we need a wide range of maleimides derivatives, particularly with linkers having alkane chain $\mathbf{4 a}$, ethers, 4b, 4c, Polyethylene Glycols (PEG), 4d and alkyne group $\mathbf{4 e}$ and ethylene glycol-OH groups compounds $\mathbf{4 f}$ and $\mathbf{4 g}$. To achieve these compounds, 
we employed most used method such as maleamic acid dehydration in presence $\mathrm{AcONa}^{11}$ (method-A) and $\mathrm{N}$-carbonyl maleimid $\mathrm{N}$-(Methoxycarbonyl) maleimide (method) ${ }^{35}$.

The maleamic acid (method-A) can be obtained from maleic anhydride under treatment of respective amines to get the maleamic acids derivatives $(3 \mathbf{a}-\mathbf{3 g}$ ). The maleamic acid derivatives $(\mathbf{3} \mathbf{a}-\mathbf{3 g})$ on treatment with sodium acetate ${ }^{11}$ to get corresponding maleimide derivatives $\mathbf{4 a - 4 g}$, the yields after purification are low particularly for 2-Bismaleimidoethane ${ }^{29}$ N-Propargylmaleimide, ${ }^{34}$ Moreover polyethylene $\mathbf{3 d}$ and free hydroxyl group substrates $\mathbf{3 f}$ and $3 g$ giving impurities.<smiles>O=C1C=CC(=O)O1</smiles>

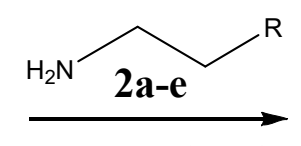

Acetone Reflux, 1h 94-99\%.
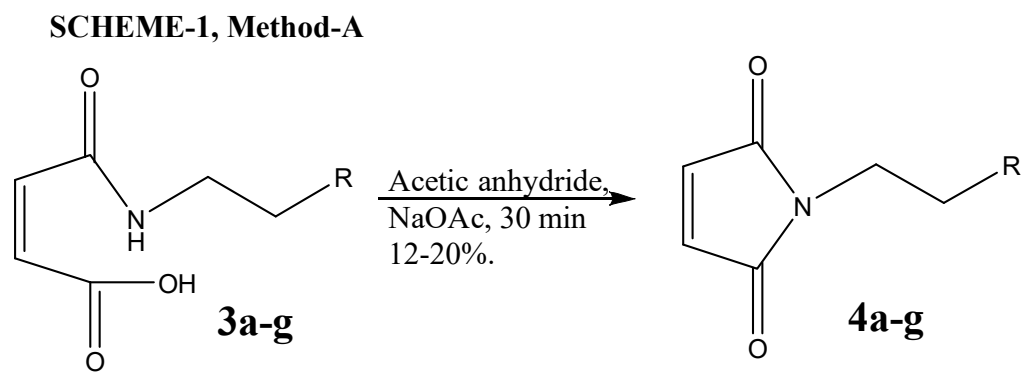

By exploring this method, (method-B) for synthesize the various maleimide derivatives by treating the free amines with $\mathrm{N}$-(Methoxycarbonyl) maleimide in most of the cases we got good to excellent yields. The hydroxyl group bearing substrate gives (4f) N-[2-(2Hydroxyethoxy)ethyl]-maleimide and $\mathbf{( 4 g ) ~} \mathrm{N}-\left(2-\right.$ Hydroxyethyl)-maleimide $^{39}$ were obtained in good to excellent yield after purification. The maleimide-YNE and polyethylene substrate are giving complex product under this condition. The NMR data shows complex structure, the absence of acetylene moiety, it indicates that is taking part in the reaction. 


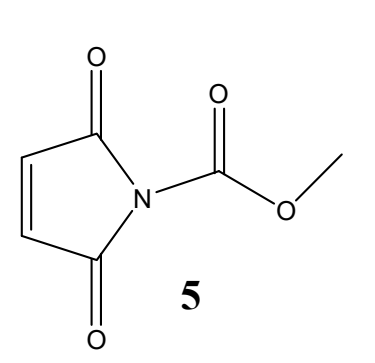

\section{SCHEME-2, Method-B}

Based on the above problems, there is need to develop a general procedure where it is compatible for alkyne group and Polyethylene group along with to avoid use of column chromatography purification. A range of methods are reported ${ }^{10,40-44}$ for cyclic dehydration, out of that para toluene sulfonic acid in toluene reflux under condition ${ }^{24,45}$ is more suitable so that by acid base $\mathrm{pH}$ manipulation we can avoid the column chromatography purification. So, we applied this method for synthesize the maleimide derivatives ((Method-C). We took bismaleimicacid $\mathbf{3 a}$ in toluene under reflux condition in presence of PTSA gives the essentially pure product but in low yield. We understood that solubility of acid bearing substrate in toluene influence the outcome (yields) of the reaction. The maleimide derivatives yields are decreasing when ether linkage is increasing in the bismaleimide because of polarity.

SCHEME-3,
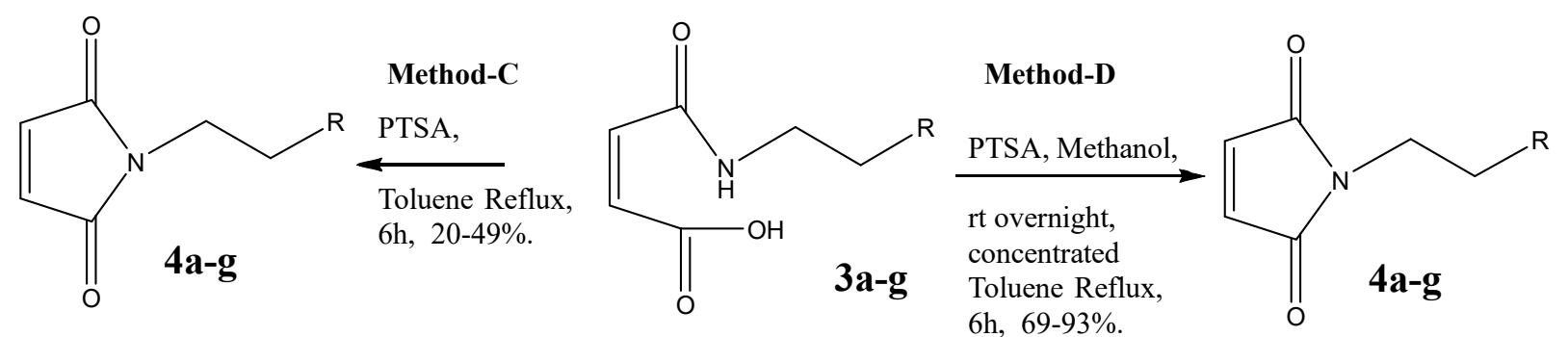

To avoid the solubility problem of maleimide acid, we carried out one pot reaction, where the acid is first is converted into ester in methanol in presence of PTSA at room temperature. After concentration $^{*}$, the crude ester in toluene under reflux condition gives required products without any column chromatography purification in good to excellent yields. (METHOD-D). 
The yields are much better than from the acid directly. Under these condition Alkyl linked maleimide $\mathbf{4 a - 4 c}$ were isolated in pure form and $\mathbf{4 c}$ was characterized by single crystal data (hard copy only). PEG-Maleimide 4d and N-Propargyl maleimide 4e gives good yields whereas as substrate $\mathbf{3 f}, \mathbf{3} \mathbf{g}$ remain unsuccessful because of free hydroxyl group, which is interfering the reaction, and giving polymeric product.

Synthesis of Maleimide derivatives from 4 Different Methods.

\begin{tabular}{|l|l|l|l|l|}
\hline & Method-A & Method-B & Method-C & Method-D \\
\hline & $16 \%$ & $71 \%$ & $21 \%$ & $\mathbf{7 0 \%}$ \\
\hline & impurities & No reaction & & \\
\hline & & & & \\
\hline
\end{tabular}


In conclusion, we have established a operationally simple one pot cyclization method for synthesis of pure maleimide derivatives without any column chromatography purification by using PTSA in presence of methanol and toluene under reflux conditions (methodD). The notable advantage of this methodology are simple conditions, industrially applicable, tolerance to a wide range of functionalities.

\section{ACKNOWLEDGMENTS}

S.R.G is thankful to Prof. Brent Sumerlin, SMU for supporting in the form of post-doctoral associate fellowship during January-2006 to December-2007 and allowing to work on this work.

\section{REFERENCE:}

1. Koniev, O.; Wagner, A., Developments and recent advancements in the field of endogenous amino acid selective bond forming reactions for bioconjugation. Chemical Society Reviews 2015, 44 (15), 5495-5551.

2. Francis, M. B.; Carrico, I. S., New frontiers in protein bioconjugation. Current Opinion in Chemical Biology 2010, 14 (6), 771-773.

3. Olson, R. A.; Levi, J. S.; Scheutz, G. M.; Lessard, J. J.; Figg, C. A.; Kamat, M. N.; Basso, K. B.; Sumerlin, B. S., Macromolecular Photocatalyst for Synthesis and Purification of Protein-Polymer Conjugates. Macromolecules (Washington, DC, U. S.) 2021, 54 (10), 48804888.

4. $\quad$ Bahou, C.; Love, E. A.; Leonard, S.; Spears, R. J.; Maruani, A.; Armour, K.; Baker, J. R.; Chudasama, V., Disulfide modified IgG1: An investigation of biophysical profile and clinically relevant Fc interactions. Bioconjugate Chem. 2019, 30 (4), 1048-1054.

5. Shoji, Y.; Otake, K.; Morishita, K.; Kitao, T. Preparation of anticancer agents modified by maleimide derivatives as protein-binding drugs for treatment of cancers. WO2019103050A1, 2019.

6. Hübner, R.; Cheng, X.; Wängler, B.; Wängler, C., Functional Hybrid Molecules for the Visualization of Cancer: PESIN-Homodimers Combined with Multimodal Molecular Imaging Probes for Positron Emission Tomography and Optical Imaging: Suited for Tracking of GRPRPositive Malignant Tissue*. Chemistry 2020, 26 (69), 16349-16356.

7. Cheronis, J. C.; Whalley, E. T.; Nguyen, K. T.; Eubanks, S. R.; Allen, L. G.; Duggan, M. J.; Loy, S. D.; Bonham, K. A.; Blodgett, J. K., A new class of bradykinin antagonists: synthesis and in vitro activity of bissuccinimidoalkane peptide dimers. J. Med. Chem. 1992, 35 (9), 156372.

8. Powell, M. J. Cyclized polypeptide prodrugs. WO9906072A1, 1999. 
9. Sun, C.; Aspland, S. E.; Ballatore, C.; Castillo, R.; Smith, A. B.; Castellino, A. J., The design, synthesis, and evaluation of two universal doxorubicin-linkers: Preparation of conjugates that retain topoisomerase II activity. Bioorg. Med. Chem. Lett. 2006, 16 (1), 104-107.

10. Xi, Z.; Cao, L. Complex molecule, and preparation method and medical composition thereof. CN102453066A, 2012.

11. Wei, L.; Cao, L.; Xi, Z., Highly Potent and Stable Capped siRNAs with Picomolar Activity for RNA Interference. Angew. Chem., Int. Ed. 2013, 52 (25), 6501-6503.

12. Kwiatkowski, M.; Sund, C. Preparation of nucleotides prodrugs. WO2018163131A1, 2018.

13. DuBay, K. H.; Iwan, K.; Osorio-Planes, L.; Geissler, P. L.; Groll, M.; Trauner, D.; Broichhagen, J., A Predictive Approach for the Optical Control of Carbonic Anhydrase II Activity. ACS Chem. Biol. 2018, 13 (3), 793-800.

14. Otsubo, T.; Tanaka, T.; Motoyanagi, J.; Minoda, M., An Alternating Glycopolymer Composed of Carbohydrate-carrying Maleimide and OH-functionalized Vinyl Ether- A New Synthetic Strategy for Glycosaminoglycan Mimics. Chem. Lett. 2019, 48 (5), 465-467.

15. Kondo, S.-i.; Kusumoto, T.; Sasai, Y.; Doi, N.; Yamauchi, Y.; Kuzuya, M., Development of polymer nano-film synthesized on self-assembled phospholipid layer possessing fluidity fabricated by plasma-assisted method. J. Photopolym. Sci. Technol. 2016, 29 (3), 439-442.

16. Durand-Silva, A.; Cortes-Guzman, K. P.; Johnson, R. M.; Perera, S. D.; Diwakara, S. D.; Smaldone, R. A., Balancing Self-Healing and Shape Stability in Dynamic Covalent Photoresins for Stereolithography 3D Printing. ACS Macro Lett. 2021, 10 (4), 486-491.

17. Sodano, H. A.; Heo, Y. Shape-memory-self-healing polymers (smshps). US20170008998A1, 2017.

18. Li, M.; De, P.; Gondi, S. R.; Sumerlin, B. S., End group transformations of RAFTgenerated polymers with bismaleimides: functional telechelics and modular block copolymers. $J$. Polym. Sci., Part A: Polym. Chem. 2008, 46 (15), 5093-5100.

19. Auvergne, R.; Morel, M.-H.; Menut, P.; Guilbert, S.; Robin, J.-J., The impact of bifunctional molecules on the gluten network during mixing. React. Funct. Polym. 2011, 71 (1), 70-79.

20. Doi, T. Nitrogen-substituted maleimide resin optical films with high heat resistance and transparency. JP2007016163A, 2007.

21. Li, M.; De, P.; Gondi, S. R.; Sumerlin, B. S., Responsive polymer-protein bioconjugates prepared by RAFT polymerization and copper-catalyzed azide-alkyne click chemistry. Macromol. Rapid Commun. 2008, 29 (12-13), 1172-1176.

22. Xu, L. Q.; Li, N. N.; Zhang, B.; Chen, J. C.; Kang, E.-T., PEGylated fluorescent nanoparticles from one-pot atom transfer radical polymerization and "click chemistry". Polymers (Basel, Switz.) 2015, 7 (10), 2119-2130.

23. Rao, V.; Navath, S.; Kottur, M.; McElhanon, J. R.; McGrath, D. V., An efficient reverse Diels-Alder approach for the synthesis of N-alkyl bismaleimides. Tetrahedron Lett. 2013, 54 (37), 5011-5013.

24. He, J.; Bai, Z.-Q.; Yuan, P.-F.; Wu, L.-Z.; Liu, Q., Highly Efficient Iridium-Based Photosensitizers for Thia-Paterno-Buchi Reaction and Aza-Photocyclization. ACS Catal. 2021, 11 (1), 446-455.

25. Han, S. H.; Mishra, N. K.; Jeon, M.; Kim, S.; Kim, H. S.; Jung, S.-Y.; Jung, Y. H.; Ku, J.-M.; Kim, I. S., Rhodium(III)-Catalyzed Diastereoselective Synthesis of 1-Aminoindanes via C-H Activation. Advanced Synthesis \& Catalysis 2017, 359 (22), 3900-3904. 
26. Salewska, N.; Milewska, M. J., Efficient method for the synthesis of functionalized basic maleimides. J. Heterocycl. Chem. 2014, 51 (4), 999-1003.

27. Mandal, T.; Das, S.; De Sarkar, S., Nickel(II) tetraphenylporphyrin as an efficient photocatalyst featuring visible light promoted dual redox activities. Adv. Synth. Catal. 2019, 361 (13), 3200-3209.

28. Galbis, E.; de-Paz, M. V.; Iglesias, N.; Lacroix, B.; Alcudia, A.; Galbis, J. A., Core crosslinked nanoparticles from self-assembling polyfma-based micelles. Encapsulation of lipophilic molecules. Eur. Polym. J. 2017, 89, 406-418.

29. Kim, Y. H.; Stites, W. E., Effects of Excluded Volume upon Protein Stability in Covalently Cross-Linked Proteins with Variable Linker Lengths. Biochemistry 2008, 47 (33), 8804-8814.

30. Hayashi, S.; Narita, A.; Wasano, T.; Tachibana, Y.; Kasuya, K.-i., Synthesis and crosslinking behavior of biobased polyesters composed of bi(furfuryl alcohol). Eur. Polym. J. 2019, $121,109333$.

31. Xi, Z.; Cao, L. Compound molecule, preparation method and pharmaceutical compositions thereof. WO2012051926A1, 2012.

32. Verbicky Jr, J. W.; Williams, L., Thermolysis of N-alkyl-substituted phthalamic acids. Steric inhibition of imide formation. The Journal of Organic Chemistry 1981, 46 (1), 175-177.

33. Yan, R.; Sander, K.; Galante, E.; Rajkumar, V.; Badar, A.; Robson, M.; El-Emir, E.; Lythgoe, M. F.; Pedley, R. B.; Årstad, E., A one-pot three-component radiochemical reaction for rapid assembly of 125I-labeled molecular probes. Journal of the American Chemical Society 2013, 135 (2), 703-709.

34. Galbis, E.; de Paz, M. V.; McGuinness, K. L.; Angulo, M.; Valencia, C.; Galbis, J. A., Tandem ATRP/Diels-Alder synthesis of polyHEMA-based hydrogels. Polym. Chem. 2014, 5 (18), 5391-5402.

35. Villemin, E.; Herent, M.-F.; Marchand-Brynaert, J., Functionalized Phosphonated HalfCage Molecules as Ligands for Metal Complexes. Eur. J. Org. Chem. 2012, 2012 (31), 61656178.

36. Nakayama, T.; Sasada, M. Ink composition with excellent ink ejection property for ink jet record and printed matter. JP2016160333A, 2016.

37. Clevenger, R. C.; Turnbull, K. D., Synthesis on N-alkylated maleimides. Synthetic Communications 2000, 30 (8), 1379-1388.

38. Sin, I. J.; Jeong, H. J.; Jo, J. W., Chemoselective Ligation of Acetylated 1maleimidosugars to Peptides for the Preparation of Neoglycopeptides. Bulletin of the Korean Chemical Society 2000, 21 (9), 845-846.

39. De, P.; Li, M.; Gondi, S. R.; Sumerlin, B. S., Temperature-Regulated Activity of Responsive Polymer-Protein Conjugates Prepared by Grafting-from via RAFT Polymerization. J. Am. Chem. Soc. 2008, 130 (34), 11288-11289.

40. Zhou, Y.; Zou, J.; Chen, L.; Song, X. Method for continuously synthesizing maleimide by using microchannel reactor. CN110683980A, 2020.

41. $\mathrm{Hu}, \mathrm{Z}$.; Wang, Y.; Luo, K.; Yu, J.; Zhu, J. Crosslinked polyamide and reinforcing fiber composite material and preparation method and application thereof. CN109134845A, 2019.

42. Gheneim, R.; Perez-Berumen, C.; Gandini, A., Diels-Alder Reactions with Novel Polymeric Dienes and Dienophiles: Synthesis of Reversibly Cross-Linked Elastomers. Macromolecules 2002, 35 (19), 7246-7253. 
43. Walker, M. A., A high yielding synthesis of $\mathrm{N}$-alkyl maleimides using a novel modification of the Mitsunobu reaction. The Journal of Organic Chemistry 1995, 60 (16), 53525355.

44. Reddy, P. Y.; Kondo, S.; Fujita, S.; Toru, T., Efficient synthesis of fluorophore-linked maleimide derivatives. Synthesis 1998, 1998 (07), 999-1002.

45. Gostl, R.; Sijbesma, R. P., pi-extended anthracenes as sensitive probes for mechanical stress. Chem Sci 2016, 7 (1), 370-375.

* Note-1: In methanol under reflux condition, aliquot NMR shows mixture of products, corresponding ester and cyclized products. To get the complete cyclized product, it is necessary to do reaction at higher temperature. To facilitate the reaction, distilled out methanol and added toluene then heated at reflux to get cyclized products in good to excellent yields. 